\title{
Expression of COX-2, p16, and Ki67 in the range from normal breast tissue to breast cancer
}

\author{
Michaela FERIANCOVÁ ${ }^{1, *}$, Ingrid WALTER ${ }^{2}$, Christian F. SINGER ${ }^{3}$, Juraj GAZDARICA ${ }^{4}$, Kamil POHLODEK ${ }^{1}$ \\ ${ }^{1} 2^{\text {nd }}$ Department of Gynecology and Obstetrics, Comenius University in Bratislava, Faculty of Medicine, Bratislava, Slovakia; ${ }^{2}$ Institute of Pathol- \\ ogy, Veterinary University Vienna, Austria; ${ }^{3}$ Medical University of Vienna, Department of Obstetrics and Gynecology, Vienna, Austria; ${ }^{4}$ Depart- \\ ment of Molecular Biology, Faculty of Natural Sciences, Comenius University in Bratislava, Bratislava, Slovakia
}

${ }^{*}$ Correspondence: michaelabart@gmail.com

Received July 31, 2020 / Accepted September 30, 2020

\begin{abstract}
The increasing number of diagnosed breast lesions lead to the critical need for new markers that would elucidate the process of tumorigenesis. The objective of the study was to examine COX-2, p16, and Ki67 expression in a broad spectrum of breast lesions in order to define the proteins' phenotype throughout the tumorigenesis. Expression was studied by immunohistochemistry in 308 human breast samples divided into 7 subgroups - flat epithelial atypia (FEA), atypical hyperplasia $(\mathrm{ADH})$, intraductal carcinoma (DCIS), invasive cancer (IC), benign lesions (BLs), normal tissue adjacent to breast cancer (CANT), and fatty tissue (FT). Analysis among 4 subgroups - premalignant lesions (DIN), IC, BLs, and normal tissue was also performed. High prevalence of COX-2 overexpression was found in all breast lesions including BLs (70\% FEA, $89 \%$ ADH, $86 \%$ DCIS, $81 \%$ IC, $44 \%$ CANT, 92\% BLs, 29\% FT). Significant dominance of p16 overexpression was found in premalignant lesions and BLs (50\% FEA, 67\% ADH, 50\% DCIS, 37\% IC, 8\% CANT, 58\% BLs, 21\% FT). The location of staining within p16+ cells differed - BLs showed nuclear positivity, whereas in IC it was exclusively cytoplasmic. Premalignant lesions showed all types of p16 positivity. Significantly higher prevalence of COX-2+p16+Ki67+ phenotype was in premalignant tumors with the highest prevalence in ADH (40\% of FEA, 67\% ADH, 35\% DCIS, 20\% IC, 3\% CANT, 20\% BLs, 14\% FT). Our observations showed a high prevalence of COX-2+p16+Ki67+ phenotype in premalignant lesions. Further studies are needed in order to elucidate if this phenotype reflects any specific pathway of future progression of premalignant breast lesions.
\end{abstract}

Key words: COX-2, p16, Ki67, tumorigenesis, breast cancer

Advances in breast cancer diagnosis are accompanied by an increasing spectrum of breast diagnoses with different prognosis. Early prediction of further biologic behavior of many of the lesions is still not possible. In many cases, the effort to ensure the local control of the disease leads to a significant "overtreatment". There is, therefore, a critical call for reliable markers that would help to understand the process beyond the breast cancer formation.

Various models of carcinogenesis have been proposed considering it is a complex event. Rising evidence points out to the process designated as "inflammogenesis of cancer" as a general model of carcinogenesis where COX-2 aberrant production and associated prostaglandin cascade seem to play a significant role [1-5].

The association between COX-2 overexpression, cancer progression, and metastasis process has been described by many studies $[6,7]$ as well as its association with poor prognosis and recurrence risk in ductal carcinoma in situ (DCIS) [8-12]. The exact role of COX-2 driven mechanisms in tumorigenesis has been studied in experimental studies $[13,14]$.

The inducible COX-2 enzyme controls much more than solely the inflammatory reaction. It modulates various molecular events necessary for homeostatic physiology (blood vessels constriction, cell division, apoptosis, and many others). Its overexpression with consecutive PGE2 synthesis leads to all important steps in cancer progression such as angiogenesis, metastasis, apoptosis, immunosuppression, and more [5]. Thus, the association between COX-2 expression and cancer formation through all breast cancer stages including different premalignant lesions was described [15, 16] and selective COX-2 inhibitors were shown to reduce the risk of breast cancer and precancerous lesions [17]. However, it is still not enough for the stratification of patients with breast lesions and therapy selection.

One of the important studies analyzing different biomarkers and breast cancer progression identified another considerable prognostic marker - p16. The p16 protein is 
an inhibitor of the cyclin-dependent kinase that blocks the G1/S phase of the cell cycle. Downregulation of the p16 protein has been reported in many malignancies [18]. On the contrary, it was found that the overexpression of p16 in patients with high proliferative activity might indicate that p16 is inactive or not sufficient to limit cell growth in breast carcinomas [19].

In the study of Kerlikowske et al. [12], the overexpression of p16 was the only individual marker associated significantly with invasive recurrence after DCIS treated by lumpectomy. In the analysis of a combination of markers, the COX-2+p16+Ki67+ phenotype correlated with the "risk" subgroup of DCIS with subsequent invasive recurrence. Ki67 as a proliferative marker provided the stratification of the "risky" p16+ phenotype. The mechanism of these proteins' overexpression in carcinogenesis is explained in detail by Gauthier [13] and is related to an abrogated reaction to cellular stress. The number of studies supporting the evidence of COX-2 or p16 role in carcinogenesis is rising; however, their results are often controversial, some of them devoted to invasive cancer, some to premalignant lesions.

In our study, we decided to map the expression of COX-2, p16, and Ki67 (individually and in combination) in different breast tissues and breast lesions in order to define their phenotype throughout tumorigenesis.

This is the first study analyzing the three biomarkers in such a broad spectrum of breast lesions and normal tissue, namely flat epithelial atypia, atypical ductal hyperplasia, in situ carcinoma, invasive breast cancer, benign lesions (adenosis, fibrocystic breast changes), normal tissue adjacent to breast cancer, and breast fatty tissue.

Another objective of the study was a possible association of these proteins' expression in different breast lesions in correlation to patients' age. It is known that the prevalence of aggressive types of breast cancer is higher in younger patients ( $<40$ years) $[20,21]$. Therefore, we analyzed the expression of COX-2, p16, and Ki67 in the subsets of tumors according to age.

\section{Materials and methods}

Sample characterization. Commercially available tissue microarrays (TMAs) with different breast lesions were purchased and used for the immunohistochemical staining: TMA BB08015 (US Biomax Inc.) with 42 samples of breast ductal intraepithelial lesions and 6 cases of breast invasive ductal carcinoma, TMA BR8011 with 50 samples of intraductal carcinoma, 4 samples of lobular carcinoma in situ and 26 samples of normal adjacent tissue to breast intraductal carcinoma (US Biomax Inc.), TMA BC08118 (US Biomax Inc.) with 90 cases of breast invasive cancer (85 cases of ductal invasive carcinoma, 5 cases of lobular invasive cancer), 10 samples of matched normal adjacent tissue, TMA BR806 (US Biomax Inc.) with 80 cases of breast hyperplasia (67 cases of adenosis, 4 samples of cystic hyper- plasia, 9 cases of fibrofatty tissue). Each analyzed TMA core included a representative part of the definite diagnosis defined after the whole lesion had been examined. One core represented one single lesion. Overall, 308 samples were examined including the following sample types ("sample type 1"): 10 cases of flat epithelial atypia (FEA), 9 cases of atypical ductal hyperplasia (ADH), 72 cases of in situ carcinomas (DCIS), 96 invasive carcinomas (IC) - 91 of ductal invasive cancer, 5 lobular invasive cancer, 36 cases of cancer adjacent normal tissue (CANT) - 26 adjacent to DCIS 10 to IC, 71 cases of benign lesions (BLs) -66 cases of adenosis, 4 samples of cystic hyperplasia, 1 case of lobular hyperplasia and 14 samples of fibrofatty tissue (FT). Due to a lower number of some sample counts, we also used a different classification of the samples ("sample type 2") with 294 samples in the following subgroups: premalignant lesions (91 cases including FEA, ADH, and DCIS samples), invasive cancer (96 cases), cancer adjacent normal tissue (36 cases), and benign lesions (71 samples). The sample types used for analysis with the exact overall numbers are shown in Table 1. Clinicopathological data were included in the identification sheets of the TMAs, however, data such as a tumor grade or TNM stage were available only for a subset

Table 1. Sample classification according to the sample type and patients' age.

\begin{tabular}{|c|c|c|c|}
\hline Sample type 1 & $\begin{array}{c}\text { Total } \\
\text { number }\end{array}$ & $\begin{array}{c}\text { Age } \\
<40 \text { years }\end{array}$ & $\begin{array}{c}\text { Age } \\
\geq 40 \text { years }\end{array}$ \\
\hline Total number & 308 & 78 & 230 \\
\hline Flat epithelial atypia & 10 & 4 & 6 \\
\hline Atypical ductal hyperplasia & 9 & 3 & 6 \\
\hline In situ carcinoma & 72 & 18 & 54 \\
\hline Ductal carcinoma in situ & 69 & 18 & 51 \\
\hline Lobular carcinoma in situ & 3 & 0 & 3 \\
\hline Invasive carcinoma & 96 & 19 & 77 \\
\hline Ductal invasive carcinoma & 91 & 17 & 74 \\
\hline Lobular invasive carcinoma & 5 & 2 & 3 \\
\hline Cancer adjacent normal tissue & 36 & 12 & 24 \\
\hline DCIS adjacent normal tissue & 26 & 8 & 18 \\
\hline IDC adjacent normal tissue & 10 & 4 & 6 \\
\hline Benign lesions & 71 & 17 & 54 \\
\hline Adenosis & 66 & 17 & 49 \\
\hline Cystic hyperplasia & 4 & 0 & 4 \\
\hline Lobular hyperplasia & 1 & 0 & 1 \\
\hline Fibrofatty tissue & 14 & 5 & 9 \\
\hline Fibrofatty tissue (breast hyperplasia) & 9 & 4 & 5 \\
\hline Fibrofatty tissue (DCIS) & 4 & 1 & 3 \\
\hline Fibrofatty tissue (LCIS) & 1 & 0 & 1 \\
\hline \multicolumn{4}{|l|}{ Sample type 2} \\
\hline Total number & 294 & & \\
\hline Premalignant lesions & 91 & 25 & 66 \\
\hline Invasive cancer & 96 & 19 & 77 \\
\hline Cancer adjacent normal tissue & 36 & 12 & 24 \\
\hline Benign lesions & 71 & 17 & 54 \\
\hline
\end{tabular}


of samples and were therefore not included in the primary analysis. All tissue was collected under the highest ethical standards with the donor being informed completely and with their written consent.

Immunohistochemistry. For COX-2 staining, first, the activity of endogenous peroxidase was blocked by the incubation in methanol $/ \mathrm{H}_{2} \mathrm{O}_{2}$ for 15 minutes followed by rinsing the section with tap water. The antigen was retrieved by heating the sections for $30 \mathrm{~min}$ in the Trilogy Buffer (Cell Marque No. 920P-04) with distilled water (dilution 1:20). After PBS washing and protein block (1.5\% Dako Goat Serum), slides were incubated overnight with the ready-to-use primary rabbit anti-COX2 antibody (SP21 Cell Marque Cat. No. 240R-17) at $4^{\circ} \mathrm{C}$. After washing in PBS, the secondary antibody (Bright Vision Poly-HRP-anti-rabbit, ImmunoLogic-Duiven, Netherlands) was applied for $30 \mathrm{~min}$ at room temperature. Slides were washed in PBS and incubated in diaminobenzidine (Sigma, D5905) for 10 minutes. After washing them in distilled water, they were counterstained with hematoxylin.

For p16 staining, the antigen was retrieved by incubation in Cell Conditioning Solution CC1 (Ventana, cat. No. 950-124) for $30 \mathrm{~min}$. After washing in PBS and protein block (1.5\% goat serum), primary ready-to-use antibody Clin Tec mouse monoclonal - anti-p16 (Ventana, cat. No. 805-4713) was applied for overnight incubation at $4^{\circ} \mathrm{C}$. After washing with PBS, the secondary antibody (Bright Vision PolyHRP-anti-rabbit, ImmunoLogic-Duiven, Netherlands) was applied for 30 minutes. The same procedure was carried out for Ki67 staining using the ready-to-use monoclonal rabbit anti-Ki67 antibody (Clone 30-9, Ventana, cat. No. 750-4286). The specificity of the antibodies used has been shown before [22-27]. Negative controls were incubated with PBS instead of the primary antibody.

Evaluation of immunostaining. Staining intensity, cellular localization (cytoplasmic, membranous, nuclear, or diffuse), and a number of positive cells were included in the expression assessment.

COX-2 staining was evaluated on a scale $0-3$ using the condensed Allred score (as in Kerlikowske trial [12]) based upon the sum of the proportion and intensity score according to the following criteria: Proportion score: $0=$ no positive cells; $1=<1 \% ; 2=1-10 \% ; 3=10-33 \% ; 4=33-66 \% ; 5=$ $>66 \%$, intensity score: $0=$ none; $1=$ weak; 2 = intermediate; 3 $=$ strong. Allred score: $0=0$; Allred $1=2,3$, 4; Allred $2=5$, 6; Allred $3=7,8$. Exemplary assessment of staining intensity of COX-2 immunohistochemistry is shown in Figure 1.

p16 staining was analyzed according to the estimated number of immunopositive cells while the staining of any intensity was evaluated as positive. The following scale was used for p16 evaluation: $0=$ no staining; $1=<25 \%$ positive cells; $2=25-75 \%$ positive cells; $3=75-100 \%$ positive cells.

For COX-2 and p16 staining, samples with overall score 2 and more were considered to overexpress the analyzed proteins.
For Ki67 expression, the sample was evaluated to show a high expression of Ki67 (later only "overexpression") if more than $10 \%$ of sample cells were stained regardless of staining intensity, the same as in the study of Kerlikowske et al. [12].

Statistical analysis. The IBM SPSS Statistics was used for statistical analysis. Contingency tables and two-sided Fisher's exact test were used for the analysis of the interrelations between the variables with a significant $\mathrm{p}$-value $<0.05$. The null hypothesis testing equal distribution of the protein overexpression between the subgroups is significant if the absolute adjusted residual is greater than 1.96 ( $\mathrm{p}$-value $<0.05$ ). We also used R software for contingency tables $2 \times 2$. Fisher's exact test was used to compare two particular groups with a significant level of 0.05 . The null hypothesis where the odds ratio $(\mathrm{OR})$ is equal to one was tested. This analysis provided $\mathrm{p}$-value, OR, and the confidence interval for the OR.

\section{Results}

When analyzing the COX-2 expression, the staining was positive in the cytoplasm and membrane of the cells (Figure 1). In the analysis of the 7 breast lesion types ("sample type 1") FEA, ADH, DCIS, IC, CANT, BLs, and FT, the distribution of COX-2 overexpression differed significantly from expected values. From the overall number of 308 samples, COX-2 was overexpressed in $70 \%$ of FEA samples (7/10), $89 \%$ of $\mathrm{ADH}$ (8/9), $86 \%$ of DCIS $(62 / 72), 81 \%$ of IC $(78 / 96), 44 \%$ of CANT (16/36), $92 \%$ of BLs (65/71), and $29 \%$ of FT (4/14) (Figure 2 ). Detailed analysis with ARs and p-values for each group can be seen in Supplementary Table S1.

p16 staining was found either in the cytoplasm, nucleus, or both cytoplasm and nucleus of the cells. Most of the BLs and CANT showed nuclear positivity. IC samples showed exclusively cytoplasmic positivity, and all types of positivity were found within FEA, ADH, and DCIS samples. Examples of p16 staining with different staining locations can be seen in Figure 3. Analysis of p16 overexpression also showed a statistically significant difference between the subgroups (Supplementary Table S1). p16 was overexpressed in 50\% of FEA (5/5), $67 \%$ of ADH (6/9), 50\% of DCIS (36/72), 37\% of IC $(35 / 96), 8 \%$ of CANT (3/36), $58 \%$ of BLs $(41 / 71)$, and $21 \%$ of FT (3/14) (Figure 2).

Ki67 showed positive nuclear staining. Overexpression also differed significantly as seen in Supplementary Table S1; Ki67 was overexpressed in $80 \%$ of FEA (8/10), $89 \%$ of $\mathrm{ADH}(8 / 9), 51 \%$ of DCIS (37/72), 37\% of IC (35/96), $3 \%$ of CANT (1/36), $27 \%$ of BLs (19/71), and in $21 \%$ of FT $(3 / 14)$ (Figure 2).

The phenotype with overexpression of all three proteins (COX-2+p16+Ki67+) was found in $40 \%$ of FEA (4/10), $67 \%$ of ADH (6/9), 35\% of DCIS (25/72), 20\% of IC (19/96), 3\% of CANT (1/36), $20 \%$ of BLs (14/71), and $14 \%$ of FT $(2 / 14)$ (Figure2). Thestatisticalanalysisdefined significantdifferences of the COX-2+p16+Ki67+ overexpression distribution due to ADH, DCIS, and CANT values (Supplementary Table S1). 

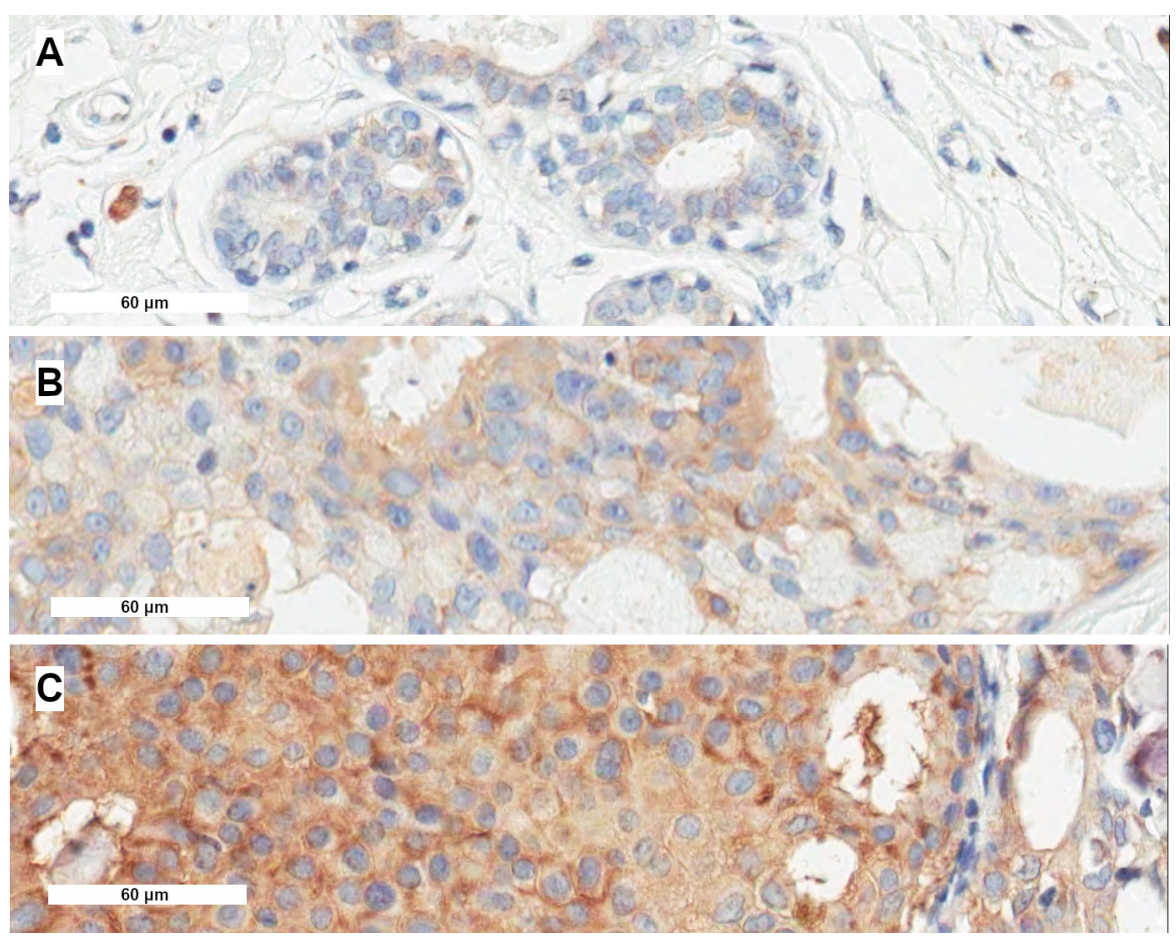

Figure 1. COX-2 immunohistochemistry, in all samples the cytoplasmic positivity can be seen. Scale bar $60 \mu \mathrm{m}$. A) Intensity score 1 (human DCIS), proportion score 4, Allred 2; B) Intensity score 2 (human DCIS), proportion score 5, Allred 3; C) Intensity score 3 (human DCIS), proportion score 5 , Allred 3
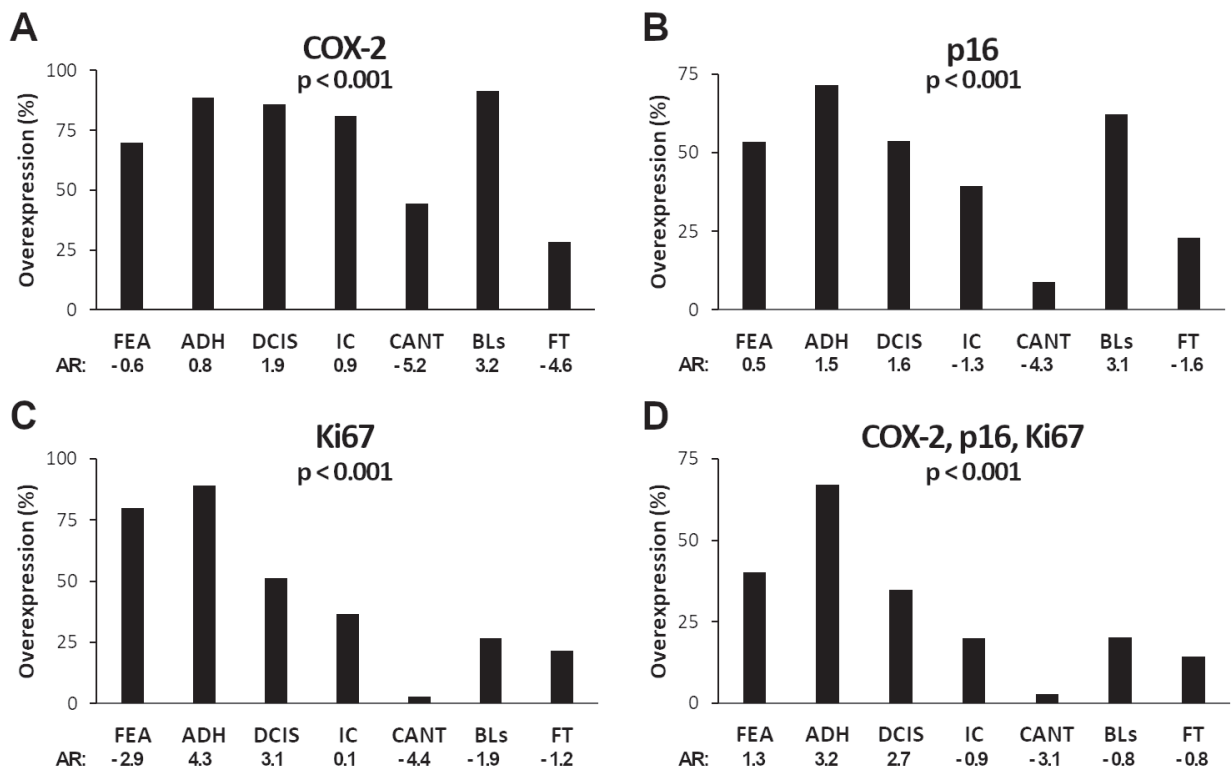

Figure 2. Distribution of COX-2 (A), p16 (B), and Ki67 (C) overexpression in different human breast tumors and normal breast tissue shown in percentual levels ("sample type 1"); D) Combination of COX-2, p16, and Ki67 overexpression. Data obtained from the analysis of interrelations between the variables using Fisher's exact test with a significant p-value $<0.05$. The p-values from the comparison of the two specific subgroups are given in Supplementary Table S3. Abbreviations: AR - adjusted ratio; FEA - flat epithelial atypia; ADH - atypical ductal hyperplasia; DCIS - ductal carcinoma in situ; IC - invasive breast cancer; CANT - cancer adjacent normal tissue; BLs - benign lesions; FT - fibrofatty tissue

In the second analysis of the four groups ("sample type 2") - premalignant lesions, invasive carcinoma (IC), cancer adjacent normal tissue (CANT), and benign lesions (BLs) COX-2 was overexpressed in $85 \%$ of premalignant lesions
(77/91), $81 \%$ of IC (78/96), $44 \%$ of CANT, and $92 \%$ of BLs (65/71). p16 was overexpressed in $52 \%$ of premalignant lesions (47/91), 37\% of IC (35/96), 8\% of CANT (3/36), and $58 \%$ of BLs (41/71). For Ki67, the results were as follows: 
overexpression was found in $58 \%$ of premalignant lesions (53/91), 37\% of IC (35/96), 3\% CANT (1/36), and $27 \%$ of BLs (19/1). All three proteins (COX-2+p16+Ki67+) were overexpressed in 39\% of premalignant lesions (35/91), $20 \%$ of IC (19/96), 3\% of CANT (1/36), and 20\% of BLs (14/71). The distribution of the protein overexpression in particular subgroups can be seen in Figure 4. Detailed statistical analysis with ARs and p-values for each group can be seen in Supplementary Table S2.

In order to see if there are significant differences between particular lesion groups, we performed a comparison using the $2 \times 2$ contingency table and found that overexpression of both COX-2 and p16 was significantly higher in premalignant tumors, invasive cancer, and benign tumors in comparison to CANT; p16 was also overexpressed significantly more often in BLs in comparison to IC. Interestingly, all three proteins were overexpressed with significantly higher frequency in premalignant lesions in comparison to all other groups (IC, CANT, and BLs); also, BLs showed significant overexpression of COX-2, p16, Ki67 in comparison to CANT. When this comparison was performed between each group from "sample type 1" analysis, ADH and DCIS showed a significantly higher presence of COX-2+p16+Ki67+ phenotype in comparison to IC, and $\mathrm{ADH}$ overexpressed COX-2+p16+Ki67+ phenotype significantly more often also than BLs. For exact data and $\mathrm{p}$-values of the analysis using the $2 \times 2$ contingency table see Supplementary Table S3 ("sample type 1") and Supplementary Table S4 ("sample type 2").

When comparing the COX-2 overexpression between younger patients $(<40$ years $)$ and patients $\geq 40$ years in different sample types, within the FEA group COX-2 was overexpressed in $50 \%$ in the younger group and in $83 \%$ of older women. In $\mathrm{ADH}$, younger groups overexpressed COX-2 in $100 \%$ versus $83 \%$ in the $\geq 40$ group, in DCIS $83 \%$ versus $87 \%$, in IC $68 \%$ versus $84 \%$. In CANT it was $25 \%$ versus $54 \%$, BLs presented also with similar overexpression rates between
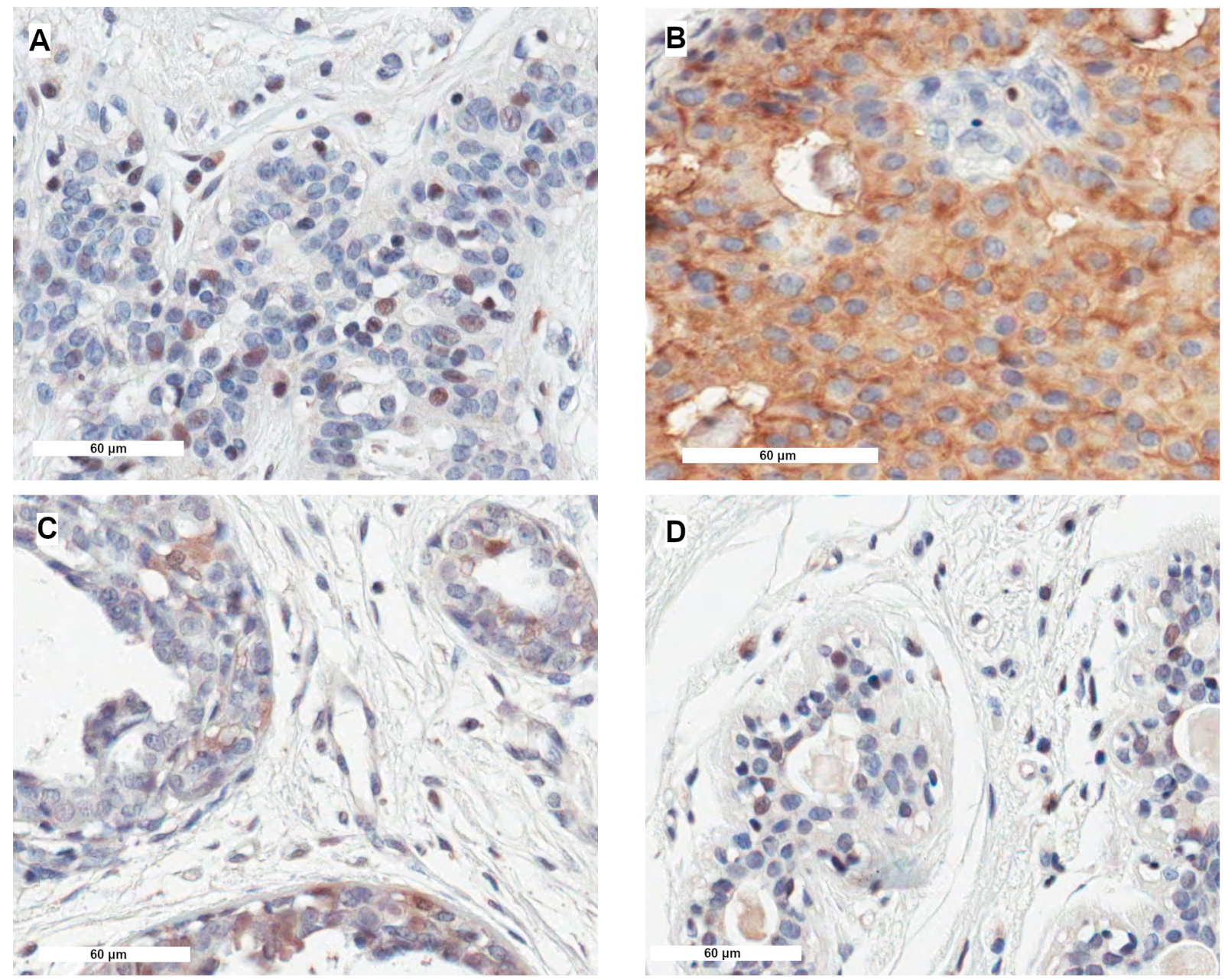

Figure 3. p16 immunohistochemical detection at a different cell site. Scale bar $60 \mu \mathrm{m}$. A) Nuclear positivity - usual hyperplasia of the human breast, score 2; B) Cytoplasmic positivity - human invasive breast cancer, score 3; C) Nuclear and cytoplasmic positivity - atypical ductal hyperplasia of the human breast, score 2; D) Nuclear positivity - atypical ductal hyperplasia of the human breast, score 1 . 
the two age groups - $94 \%$ versus $91 \%$ and fatty tissue showed COX-2 overexpression in $20 \%$ of younger patients and $33 \%$ in the older ones.

As for p16, the overexpression in the analyzed lesion groups was almost the same in both age subgroups: for FEA $50 \%$ in both subgroups ( $<40$ years and $\geq 40$ years), for $\mathrm{ADH}$ $67 \%$ and $65 \%$, respectively, for DCIS $50 \%$ in both subgroups, IDC $32 \%$ versus $38 \%$, CANT $8 \%$ and $9 \%$, respectively, BLs $53 \%$ versus $60 \%$ and for fatty tissue the overexpression was $20 \%$ and $22 \%$, respectively.

Ki67 was overexpressed in FEA with 50\% frequency within $<40$ years group and $100 \%$ in $\geq 40$ years group. $\mathrm{ADH}$ group showed overexpression in $100 \%$ of $<40$ years and $83 \%$ of $\geq 40$ years. For DCIS, the overexpression was $44 \%$ in $<40$ years and $54 \%$ in $\geq 40$ years. Frequency in the IDC group was similar between the age groups $-32 \%$ and $38 \%$, respectively. In the CANT group $8 \%$ of $<40$ years patients overexpressed $\mathrm{Ki67}$, and none of the older patients overexpressed Ki67 in CANT. Benign lesions showed 35\% of Ki67 overexpression within the younger group and $24 \%$ in the group $\geq 40$ years. Overexpression in fatty tissue was similar - $20 \%$ in the younger group and $22 \%$ in older patients.

As for the phenotype COX-2+, p16+, Ki67+, the expression between the age groups was the following: FEA 53\% in $<40$ years, $33 \%$ in $\geq 40$ years, $\mathrm{ADH}$ the same expression. $67 \%$ for both age subgroups, DCIS 39\% in $<40$ years, $33 \%$ in $\geq 40$ years, IDC $16 \%$ in $<40$ years, $21 \%$ in $\geq 40$ years. For CANT overexpression of all three proteins was $8 \%$ in the younger group and none in the older one, BLs $30 \%$ versus $17 \%$, and fatty tissue $20 \%$ in younger and $11 \%$ in older patients.

\section{Discussion}

Our study showed several interesting findings. We observed high COX-2 expression in almost all breast lesions - particularly ADH, DCIS, but also in benign lesions (Figure 2). In contrast to other studies, we also observed a high expression rate of COX-2 in IDC (81\%) (Figure 2). Spizzo et al. [28] refer COX-2 overexpression in $48 \%$ of IDC samples, Ristimäki et al. [16] showed $38 \%$ of breast cancer to overexpress COX-2 and commented that COX-2 is exclusively a feature of the malignant but not benign epithelium of the breast. Davies et al. [29] observed COX-2 expression in $80 \%$ of invasive breast tumors, whereas $54 \%$ showed strong positivity. On the other hand, Nassar et al. [30] described that $95 \%$ of breast cancer showed cytoplasmic COX-2 expression, which depended on the tumor size and grade.

The studies of a COX-2 role in breast cancer are rather controversial, and their data concerning COX-2 expression are various, from which emerges that COX-2 expression should be formulated with caution and in a wider context. Fornetti et al. [31] pointed out various differential baseline levels of COX-2 expression in premenopausal women, which can be influenced by ovarian hormones. Data from his cohort show that as many as $30 \%$ of young women have
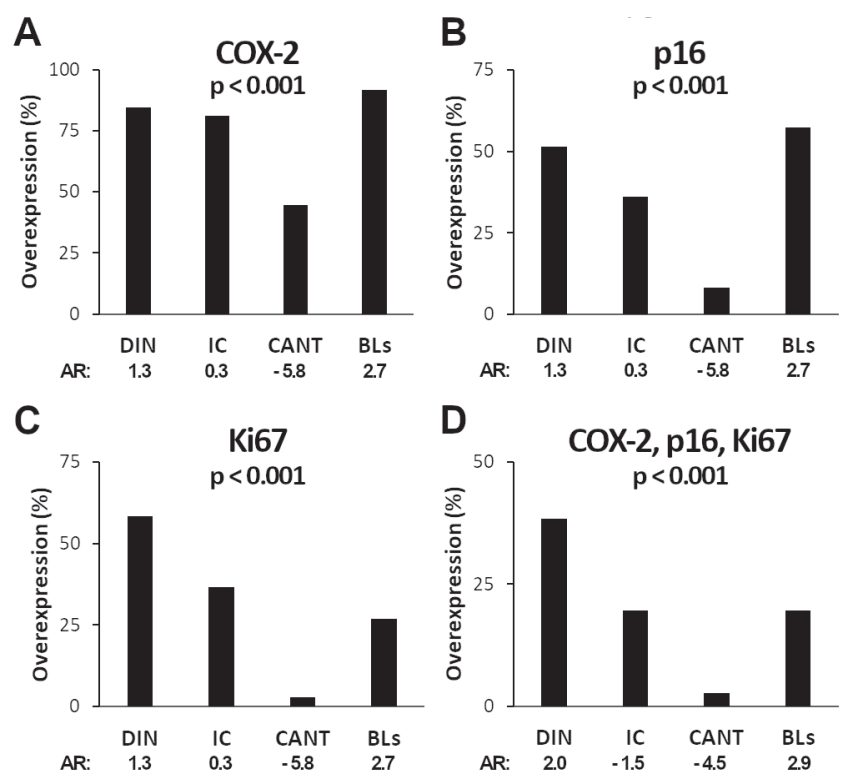

Figure 4. Distribution of COX-2 (A), p16 (B), and Ki67 (C) overexpression in different human breast tumors and normal breast tissue, percentual levels ("sample type 2"); D) Combination of COX-2, p16, and Ki67 overexpression. Data obtained from the analysis of interrelations between the variables using Fisher' exact test with significant p-value $<0.05$. The p-values from the comparison of the two specific subgroups are given in Supplementary Table S4. Abbreviations: AR - adjusted ratio; DIN ductal intraepithelial neoplasia (refers to "premalignant lesions" in the text); IC - invasive breast cancer; CANT - cancer adjacent normal tissue; BLs - benign lesions.

a high baseline of the COX-2 expression [31]. They found that COX-2 expression in the normal breast epithelium paralleled COX-2 expression in DCIS and IDC (matched in the same patients) and thus physiologic regulators of COX-2 expression in normal tissue also influence DCIS and IDC COX-2 levels.

Our study revealed COX-2 overexpression also in benign breast lesions. Other studies showing that COX-2 overexpression is not solely the feature of the malignant events have been published. Decker et al. [32] published the first study to show that aberrant COX-2 expression also contributes to the development of fibrocystic changes. In the study in mice, aberrant COX-2 overexpression caused cystic duct dilatation, adenosis, and fibrosis, whereas carcinomas developed rarely. Strong COX-2 expression was observed in fibrocystic changes also when compared to low expression in normal breast epithelium [32]. This is in parallel to the results of our study in human breast cancer where the COX-2 overexpression was observed in a significant proportion of benign tumors (adenosis, cystic hyperplasia, and lobular hyperplasia).

Our finding of the COX-2 expression in a subset of normal breast tissue may be explained by the study of normal human mammary epithelial cells (hMECs), cells obtained from 
reduction mammoplasty [14]. It was found that within these cells, a population of cells emerges that continue to proliferate further in in vitro conditions in comparison to the others and the cells divide into "preselection" and "postselection" cells. The postselection cells were identified as the potential to acquire a phenotype associated with malignant cells. Crawford et al. [14] carried out microarray analysis of preselection and postselection cells and identified a COX-2 gene as one of the genes that were overexpressed in postselection cells. The authors showed that postselection cells have the more angiogenic and invasive capability as compared with preselection cells and thus concluded that COX-2 expression may provide susceptibility to transformation. However, Zhao et al. [33] found that hMECs express similar levels of COX-2 in both preselection and postselection stages. Zhao et al. believe the discrepancy of the results with that of Crawford et al. [14] may come from the different culture conditions.

Another studied protein was p16. The p16INK4a is a tumor suppressor gene, which blocks the G1/S phase of the cell cycle, resulting in a G1 arrest. Induction of the cell senescence is one of the well-known barriers to carcinogenesis [13], and thus, p16 has been an important target in studies concerning carcinogenesis. Based on this fact, one would expect that tumors overexpressing p16 would be less likely to proceed into an invasive lesion. However, studies on p16 expression in breast cancer $[12,13]$ revealed that p16 might belong to two opposing phenotypes. It may either work as described above and lead to a proliferative arrest or, in case of abrogation of p16 signaling, thus a compromised $\mathrm{Rb}$ signaling will lead to overexpression of p16 in cells, which continue to proliferate and bypass the senescence [13]. This was confirmed in DCIS studies, where p16+Ki67+ phenotype defined DCIS tumors, which developed subsequent tumors, and of these tumors, most were invasive [13]. Gauthier et al. [14] found that high p16 expression in abrogated p16 signaling was also accompanied by COX-2 overexpression. One of the largest studies of multiple markers associated with recurrence after DCIS was performed by Kerlikowske et al. [12]. In a cohort of 329 DCIS cases treated by lumpectomy alone, Kerlikowske et al. [12] identified a combination of markers that were predictive of invasive recurrence after DCIS. The risk of subsequent invasive cancer was statistically significantly higher for women with initial DCIS lesions that were p16, COX-2, and Ki67 triple positive (p16+COX-2+Ki67+). A followup analysis of the study of Kerlikowske et al. [34] with an additional 5 years of outcome data and 442 new cases added found that p16 positivity was associated with both local and regional/metastatic invasive recurrence.

Based on the data from the study of Kerlikowske et al. [12], our previous study [35] analyzed COX-2, p16, and Ki67 expression in in situ lesions within tumors of a different stage of invasiveness: pure DCIS, microinvasive carcinoma, and invasive ductal carcinoma (IDC) with extensive in situ component (EIC). The results did not find significant differ- ences of the expression levels among the tumors, however, we observed a correlation of the p16+ and p16+COX-2+ phenotypes with the severity of the diagnosis. The highest number of p16/p16 and COX-2 overexpressing cells was in EIC within the IDC group, the lowest in pure DCIS. When analyzing the distribution of p16 expression score of the immunohistochemistry evaluation system, score 1 was the only variable that differed significantly among the tumors (the highest in DCIS < microinvasive tumor < IDC with EIC). There was no difference in Ki67 expression in relation to the tumor type. Despite the limitation of the study coming from a small number of samples, we supposed the data might indicate an association of p16 and COX-2 in combination with p16 with the surrounding tissue, which may determine the biological behavior of in situ lesions in the future [35]. When comparing the abundance of p16 overexpression with our current study, we found a higher number of DCIS tumors overexpressing p16 in the current study $(36 / 72 ; 50 \%)$ in comparison to the previous data $(4 / 15 ; 26.7 \%)$ and also a higher proportion of COX-2 overexpressing cells in DCIS ( $86 \% ; 62 / 72$ versus $24 \% ; 6 / 15$ in the previous study). The differences may be explained by a small number of samples in the previous study, different staining specificity/sensitivity, or possible different proportion of high-grade DCIS/ its molecular subtypes. We did not compare other data from our studies due to the different nature of the sample types and because of the fact that expression patterns were studied solely in the in situ parts in the first study.

The relation between the molecular subtypes and COX-2, p16, and Ki67 expression described Perez et al. [36], who evaluated COX-2, p16, and Ki67 in a subset of highgrade DCIS-in pure DCIS and DCIS associated with IDC. The study did not observe a significant difference in the frequency of the biomarkers between these subgroups, but the analysis among different molecular subtypes showed that basal phenotype was associated with higher frequency of p16 positivity (83\%) and also co-expression of COX-2, p16, and Ki67 occurred with a higher frequency in basal phenotype (33.3\%) in comparison to luminal A (1.4\%) [36].

Interesting work has been performed by $\mathrm{Di}$ Vinci et al. [37] and her group analyzing the methylation and p16 expression of the $p 16$ gene in benign (fibroadenoma) and malignant tumors (invasive) and in normal adjacent tissue. While hypermethylation of the p16INK4a promoter was common and occurred with similar frequency in all types of samples, p16 overexpression was higher in breast carcinoma than in fibroadenoma or normal tissue. Moreover, protein sequestration in a subset of fibroadenomas with high p16 expression was solely in the nucleus while cytoplasmic sequestration was found to be a feature of breast carcinoma. Their results also suggest that p16 protein loss of function may occur by cytoplasmic sequestration rather than by mutational or transcriptional inactivation and points to the sense of immunohistochemical analysis of the p16 protein as a marker of carcinogenesis. 
When analyzing the p16 positivity in our study, benign lesions such as breast hyperplasia or adenosis showed a relatively high proportion of p16+ cells, but generally, the cells showed the lower intensity of p16 staining and the positivity was nuclear (Figure 3). Invasive cancer was characterized by cytoplasmic staining, and premalignant lesions showed all types of positivity - cytoplasmic, nuclear, or both nuclear and cytoplasmic (Figure 3).

Di Vinci et al. [37] also commented on the various data from p16 studies since the immunoreactivity of p16 proteins has been reported to be variable according to different anti-p16 antibodies. Radisky et al. [38] also alert that p16 levels have been shown to increase with age in different tissue types and that p16 expression is increased in aging tissue. However, we did not find any significant difference in p16 expression depending on age.

In our study, we found a significantly higher expression of p16 in premalignant lesions (Figure 4) in comparison to IC and normal tissue. Detailed analysis of the p16 overexpression showed the highest rate of p16 overexpression was in the $\mathrm{ADH}$ group (Figure 2). It is known that $\mathrm{ADH}$ increases 4-5-fold the risk of developing cancer within 5 years [39]. However, the studies related to $\mathrm{ADH}$ markers are limited due to a small number of available samples and low-resolution methodology [40].

There are several limitations of the study. One comes from a relatively small number of the samples in some subgroups as well as a possible limitation of the specificity of available antibodies. We could not compare the expression of biomarkers in lesion groups in relation to other variables such as tumor grade or hormonal status. On the other hand, this would even reduce the number of samples in the groups and make the results more difficult to interpret. Therefore, we decided to analyze the expression of the biomarkers and their combinations independent from other variables. The COX-2+p16+Ki67+ phenotype was present with significant predominance in the premalignant group, particularly ADH, in comparison to all other lesions, followed by FEA, DCIS, IDC, benign lesions, and CANT.

In conclusion, our study confirmed the overexpression of COX-2 in all lesion types throughout tumorigenesis as well as in benign lesions confirming the affirmation that it is not exclusively a feature of invasive cancer but plays an important role in other lesion formation and exists in normal breast cells. We found a significant dominance of p16 overexpression in premalignant lesions, namely $\mathrm{ADH}$. When analyzing the staining sequestration, p16 positivity in benign lesions was exclusively nuclear, invasive cancer showed cytoplasmic positivity, and premalignant lesions showed either nuclear, cytoplasmic, or mixed cytoplasmic and nuclear positivity. These data point out that also the site of the staining may play an important role and should be considered as possibly being predictive of future behavior. COX-2+p16+Ki67+ phenotype, which was so far identified by Kerlikowske et al. [12] to be prognostic for DCIS invasive recurrence, was found with high frequency in premalignant lesions, particularly ADH, in our study. These observations need to be studied further in order to answer the question if this profile reflects some specific pathway of possible future progression of premalignant lesions and may be typical to the tissue apt to the transformation changes.

Supplementary information is available in the online version of the paper.

Acknowledgments: The authors thank C. Höchsmann from the Institute of Pathology, Veterinary University Vienna, Austria for her excellent technical support in histology and immunohistochemistry.

\section{References}

[1] KOKI AT, LEAHY KM, HARMON JM, MASFERRER JL. Cyclooxygenase-2 and cancer. In: Harris RE, editors. COX2 Blockade in Cancer Prevention and Therapy. Totowa, NJ: Humana Press, 2002: 185-203.

[2] JANG BC, HLA T. Regulation of expression and potential carcinogenic role of cyclooxygenase-2, pp 171-184. In: RE Harris (Ed.). COX-2 Blockade in Cancer Prevention and Therapy. Humana Press, 2003, p. 371. ISBN 978-1-58829-010-6

[3] HARRIS RE. Cyclooxygenase-2 blockade in cancer prevention and therapy: widening the scope of impact, pp 341-365. In: RE Harris (Ed.). COX-2 Blockade in Cancer Prevention and Therapy. Humana Press, 2003, p. 371. ISBN 978-158829-010-6.

[4] HARRIS RE. Cyclooxygenase-2 (cox-2) and the inflammogenesis of cancer. Subcell Biochem 2007; 42: 93-126. https:// doi.org/10.1007/1-4020-5688-5_4

[5] HARRIS RE, CASTO BC, HARRIS ZM. Cyclooxygenase-2 and the inflammogenesis of breast cancer. World J Clin Oncol 2014; 5: 677-692. https://doi.org/10.5306/wjco.v5.i4.677

[6] DENKERT C, WINZER KJ, MÜLLER BM, WEICHERT W, PEST $S$ et al. Elevated expression of cyclooxygenase- 2 is a negative prognostic factor for disease free survival and overall survival in patients with breast carcinoma. Cancer 2003; 97: 2978-2987. https://doi.org/10.1002/cncr.11437

[7] SHIM JY, AN HJ, LEE YH, KIM SK, LEE KP et al. Overexpression of cyclooxygenase- 2 is associated with breast carcinoma and its poor prognostic factors. Mod Pathol 2003; 16: 11991204. https://doi.org/10.1097/01.MP.0000097372.73582.CB

[8] BOLAND GP, BUTT IS, PRASAD R, KNOX WF, BUNDRED NJ. COX-2 expression is associated with an aggressive phenotype in ductal carcinoma in situ. Br J Cancer 2004; 90: 423-429. https://doi.org/10.1038/sj.bjc.6601534

[9] TAN KB, YONG WP, PUTTI TC. Cyclooxygenase-2 expression: a potential prognostic and predictive marker for high- grade ductal carcinoma in situ of the breast. Histopathology 2004; 44: 24-28. https://doi.org/10.1111/j.13652559.2004.01774.x

[10] SHIFF SJ, RIGAS B. The role of cyclooxygenase inhibition in the antineoplastic effects of nonsteroidal antiinflammatory drugs (NSAIDs). J Exp Med 1999; 190: 445-450. https://doi. org/10.1084/jem.190.4.445 
[11] SUBBARAMAIAH K, DANNENBERG AJ. Cyclooxygenase 2: a molecular target for cancer prevention and treatment. Trends Pharmacol Sci 2003; 24: 96-102. https://doi. org/10.1016/S0165-6147(02)00043-3

[12] KERLIKOWSKE K, MOLINARO AM, GAUTHIER ML, BERMAN HK, WALDMAN F et al. Biomarker Expression and Risk of Subsequent Tumors after Initial Ductal Carcinoma In Situ Diagnosis. J Natl Cancer Inst 2010; 102: 627-637. https://doi.org/10.1093/jnci/djq101

[13] GAUTHIER ML, BERMAN HK, MILLER C, KOZAKIEWICZ K, CHEW K et al. Abrogated stress response distinguishes basal-like tumors and DCIS lesions associated with subsequent tumor events. Cancer Cell 2007; 12: 479-491. https://doi.org/10.1016/j.ccr.2007.10.017

[14] CRAWFORD YG, GAUTHIER ML, JOUBEL A, MANTEI K, KOZAKIEWICZ K et al. Histologically normal human mammary epithelia with silenced p16INK4a overexpress COX-2, promoting a premalignant program. Cancer Cell 2004; 5: 5263-5273. https://doi.org/10.1016/s15356108(04)00023-6

[15] SOSLOW RA, DANNENBERG AJ, RUSH D, WOERNER BM, KHAN KN et al. COX-2 is expressed in human pulmonary, colonic, and mammary tumors. Cancer 2000; 89: 2637-2645. https://doi.org/10.1002/10970142(20001215)89:12<2637::aid-cncr17>3.0.co;2-b

[16] RISTIMÄKI A, SIVULA A, LUNDIN J, LUNDIN M, SALMINEN T et al. Prognostic significance of elevated cyclooxygenase-2 expression in breast cancer. Cancer Res 2002; 62: 632-635.

[17] HARRIS RE, CASTO BC, HARRIS ZM. Cyclooxygenase-2 and the inflammogenesis of breast cancer. World J Clin Oncol 2014; 5: 677-692. https://doi.org/10.5306/wjco. v5.i4.677

[18] HERMAN JG, MERLO A, MAO L, LAPIDUS RG, ISSA JP et al. Inactivation of the CDKN2/p16/MTS1 gene is frequently associated with aberrant DNA methylation in all common human cancers. Cancer Res 1995; 55: 4525-4530.

[19] LEE JJ, KO E, CHO J, PARK HY, LEE JE et al. Methylation and Immunoexpression of p16(INK4a) Tumor Suppressor Gene in Primary Breast Cancer Tissue and Their Quantitative p16(INK4a) Hypermethylation in Plasma by RealTime PCR. Korean J Pathol 2012; 46: 554-561. https://doi. org/10.4132/KoreanJPathol.2012.46.6.554

[20. ASSI HA, KHOURY KE, DBOUK H, KHALIL LE, MOUHIEDDINE TH et al. Epidemiology and prognosis of breast cancer in young women. J Thorac Dis 2013; 5: S2-S8. https://doi.org/10.3978/j.issn.2072-1439.2013.05.24

[21] BRANDT J, GARNE JP, TENGRUP I, MANJER J. Age at diagnosis in relation to survival following breast cancer: a cohort study. World J Surg Oncol 2015; 13: 33. https://doi. org/10.1186/s12957-014-0429-x

[22] GALLO O, MASINI E, BIANCHI B, BRUSCHINI L, PAGLIERANI $M$ et al. Prognostic significance of cyclooxygenase- 2 pathway and angiogenesis in head and neck squamous cell carcinoma. Hum Pathol 2002; 33: 708-714. https://doi. org/10.1053/hupa.2002.125376
[23] STOEHLMACHER J, LENZ HJ. Cyclooxygenase-2 inhibitors in colorectal cancer. Semin Oncol 2003; 30: 10-16. https://doi.org/10.1016/s0093-7754(03)00120-9

[24] WINDER A, MANIAR K, WEI J, LIU D, SCHOLTENS D et al. Synuclein-Î in uterine serous carcinoma impacts survival: An NRG Oncology/Gynecologic Oncology Group study. Cancer 2017; 123: 1144-1155. https://doi.org/10.1002/ cncr.30477

[25] LEFEVRE M, ROUSSEAU A, RAYON T, DALSTEIN V, CLAVEL $C$ et al. Epithelial to mesenchymal transition and HPV infection in squamous cell oropharyngeal carcinomas: the papillophar study. Br J Cancer 2017; 116: 362-369. https://doi.org/10.1038/bjc.2016.434

[26] KENG PC, SIEMANN DW. Measurement of proliferation activitiesin human tumor models: a comparison offlow cytometric methods. Radiat Oncol Investig 1998; 6: 120-127. https:// doi.org/10.1002/(SICI)1520-6823(1998)6:3<120::AIDROI2>3.0.CO;2-\#

[27] REY A, LARA PC. Ki67 proliferation index in tumors of the upper urinary tract as related to established prognostic factors and long-term survival. Arch Esp Urol 1998; 51: 204210.

[28] SPIZZO G, GASTL G, WOLF D, GUNSILIUS E, STEURER $\mathrm{M}$ et al. Correlation of COX-2 and Ep-CAM overexpression in human invasive breast cancer and its impact on survival. Br J Cancer 2003; 24; 88: 574-578. https://doi.org/10.1038/ sj.bjc. 6600741

[29] DAVIES G, SALTER J, HILLS M, MARTIN LA, SACKS N et al. Correlation between cyclooxygenase-2 expression and angiogenesis in human breast cancer. Clin Cancer Res 2003; 9: 2651-2656.

[30] NASSAR A, RADHAKRISHNAN A, CABRERO IA, COTSONIS G, COHEN C. COX-2 expression in invasive breast cancer: correlation with prognostic parameters and outcome. Appl Immunohistochem Mol Morphol 2007; 15: 255-259. https://doi.org/10.1097/01.pai.0000213130.63417.b3

[31] FORNETTI J, JINDAL S, MIDDLETON KA, BORGES VF, SCHEDIN P. Physiological COX-2 Expression in Breast Epithelium Associates with COX-2 Levels in Ductal Carcinoma in Situ and Invasive Breast Cancer in Young Women. Am J Pathol 2014; 184:1219-1229. https://doi.org/10.1016/j.ajpath.2013.12.026

[32] MÜLLER-DECKER K, BERGER I, ACKERMANN K, EHEMANN V, ZOUBOVA $S$ et al. Cystic duct dilatations and proliferative epithelial lesions in mouse mammary glands upon keratin 5 promoter-driven overexpression of cyclooxygenase-2. Am J Pathol 2005; 166: 575-584. https://doi. org/10.1016/S0002-9440(10)62279-1

[33] ZHAO X, GOSWAMI M, POKHRIYAL N, MA H, DU H et al. Cyclooxygenase-2 Expression during Immortalization and Breast Cancer Progression. Cancer Res 2008; 68: 467475. https://doi.org/10.1158/0008-5472.CAN-07-0782

[34] MOLINARO AM, SISON JD, LJUNG BM, TLSTY TD, KERLIKOWSKE K. Risk prediction for local versus regional/ metastatic tumors after initial ductal carcinoma in situ diagnosis treated by lumpectomy. Breast Cancer Res Treat 2016; 157: 351-361. https://doi.org/10.1007/s10549-016-3814-Z 
[35] BARTOVA M, ONDRIAS F, MUY-KHENG T, KASTNER M, SINGER CH, POHLODEK K. COX-2, p16 and Ki67 expression in DCIS, microinvasive and early invasive breast carcinoma with extensive intraductal component. Bratisl Lek Listy 2014; 115: 445-451. https://doi.org/10.4149/ bll_2014_088

[36] PEREZ AA, BALABRAM D, ROCHA RM, SOUZA AS, GOBBI H. Co-Expression of p16, Ki67 and COX-2 Is Associated with Basal Phenotype in High-Grade Ductal Carcinoma In Situ of the Breast. J Histochem Cytochem 2015; 63: 408-416. https://doi.org/10.1369/0022155415576540

[37] DI VINCI A, PERDELLI L, BANELLI B, SALVI S, CASCIANO I et al. p16(INK4a) promoter methylation and protein expression in breast fibroadenoma and carcinoma. Int J Cancer 2005; 114: 414-421. https://doi.org/10.1002/ijc.20771
[38] RADISKY DC, SANTISTEBAN M, BERMAN HK, GAUTHIER ML, FROST MH et al. p16INK4a Expression and Breast Cancer Risk in Women with Atypical Hyperplasia. Cancer Prev Res 2011; 4: 1953-1960. https://doi.org/10.1158/19406207.CAPR-11-0282

[39] DUPONT WD, PAGE DL. Risk factors for breast cancer in women with proliferative breast disease. $\mathrm{N}$ Engl J Med 1985; 312: 146-151. https://doi.org/10.1056/ NEJM198501173120303

[40] KADER T, HILL P, RAKHA EA, CAMPBELL IG, GORRING KL. Atypical ductal hyperplasia: update on diagnosis, management, and molecular landscape. Breast Cancer Res 2018; 20: 39. https://doi.org/10.1186/s13058-018-0967-1 


\section{Expression of COX-2, p16, and Ki67 in the range from normal breast tissue to breast cancer}

Michaela FERIANCOVÁ ${ }^{1, *}$, Ingrid WALTER ${ }^{2}$, Christian F. SINGER ${ }^{3}$, Juraj GAZDARICA ${ }^{4}$, Kamil POHLODEK ${ }^{1}$

\section{Supplementary Information}

Supplementary Table S1. Analysis of COX-2, p16, Ki67 and COX-2+p16+Ki67+ overexpression in "sample type 1“ groups using Fisher's Exact Test.

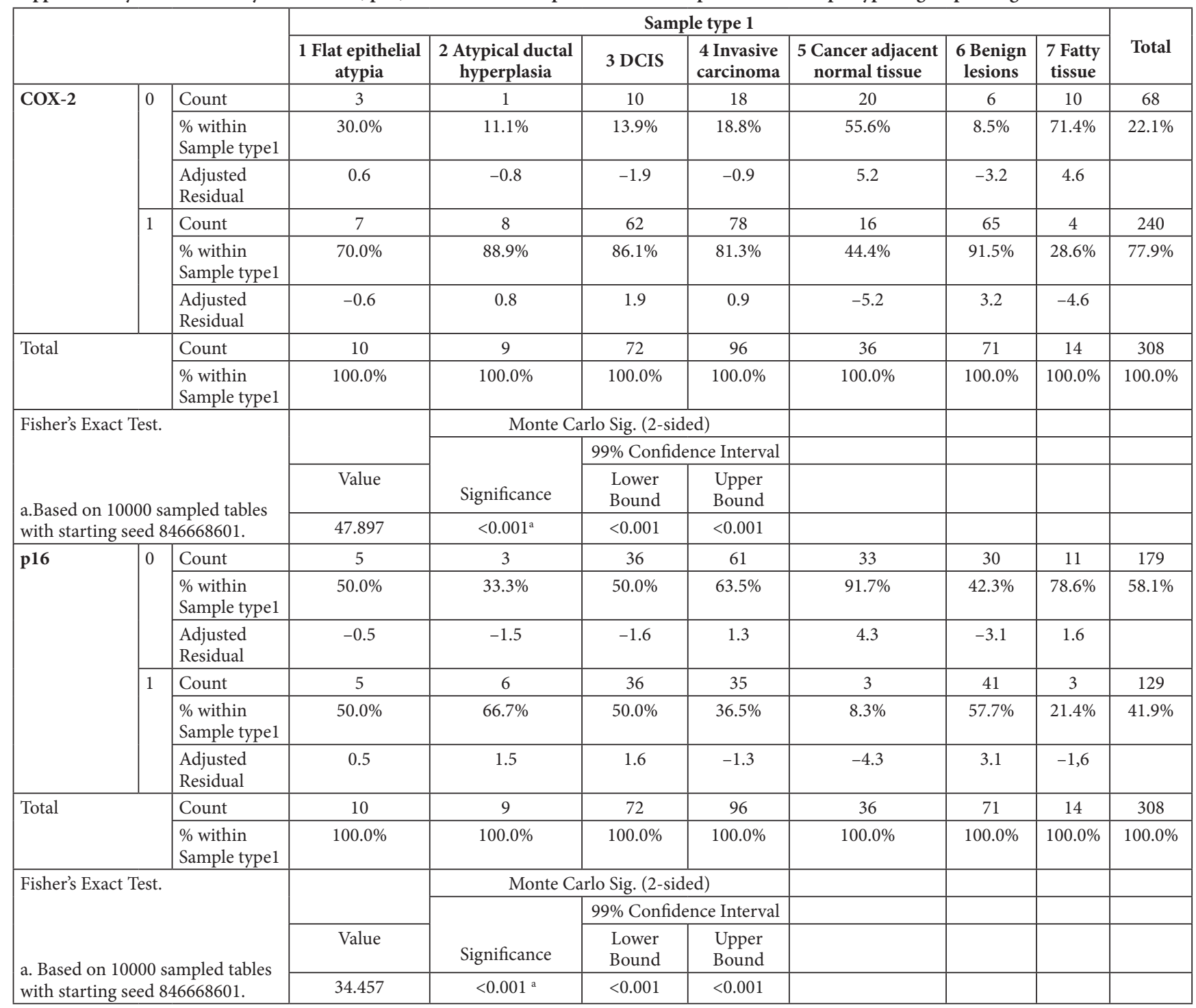


Supplementary Table S1. Continued ...

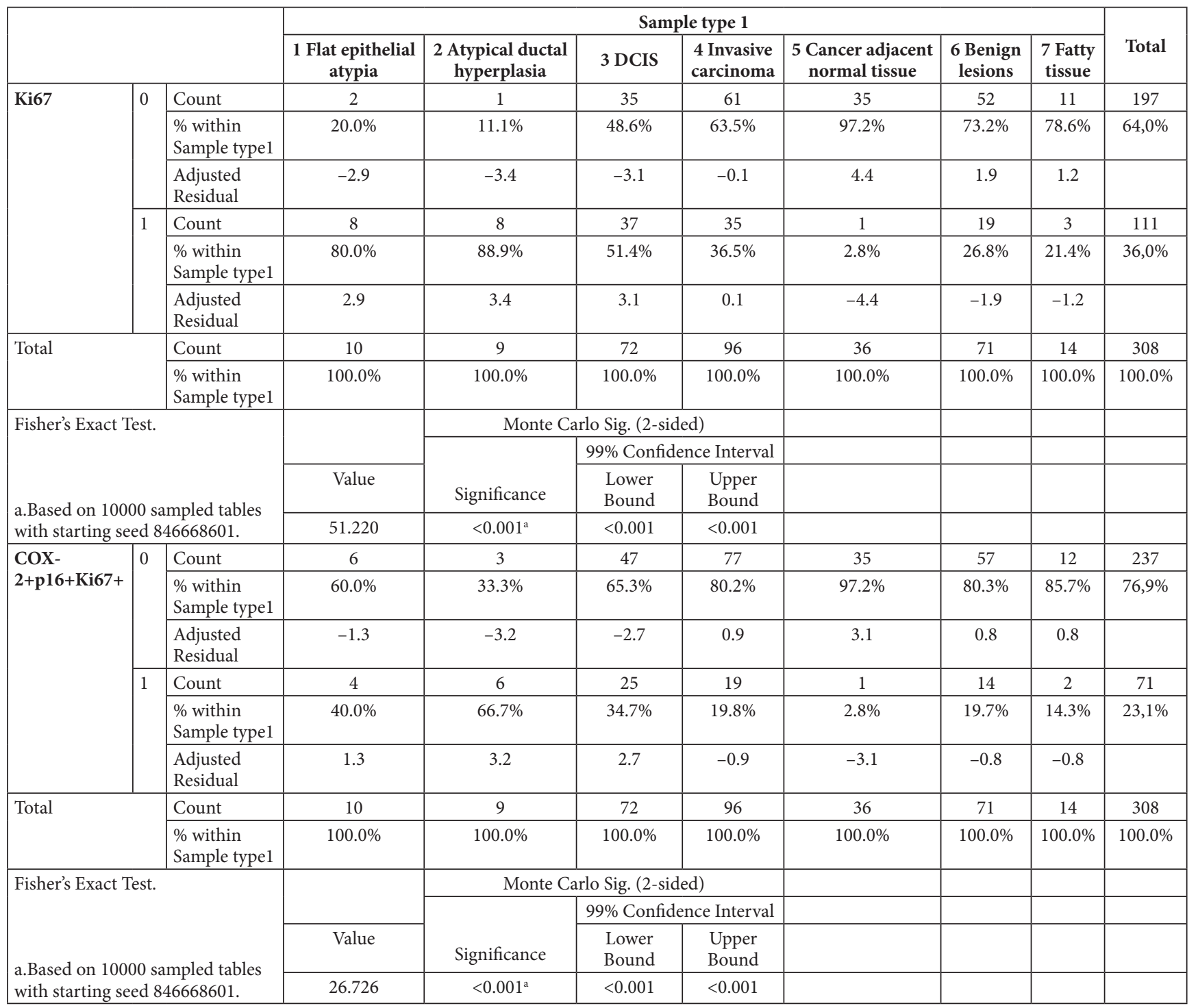

Abbreviations: $0=$ protein is not overexpressed; $1=$ protein overexpression 
Supplementary Table S2. Analysis of COX-2, p16, Ki67 and COX-2+p16+Ki67+ overexpression in "sample type 2“ groups using Fisher's Exact Test.

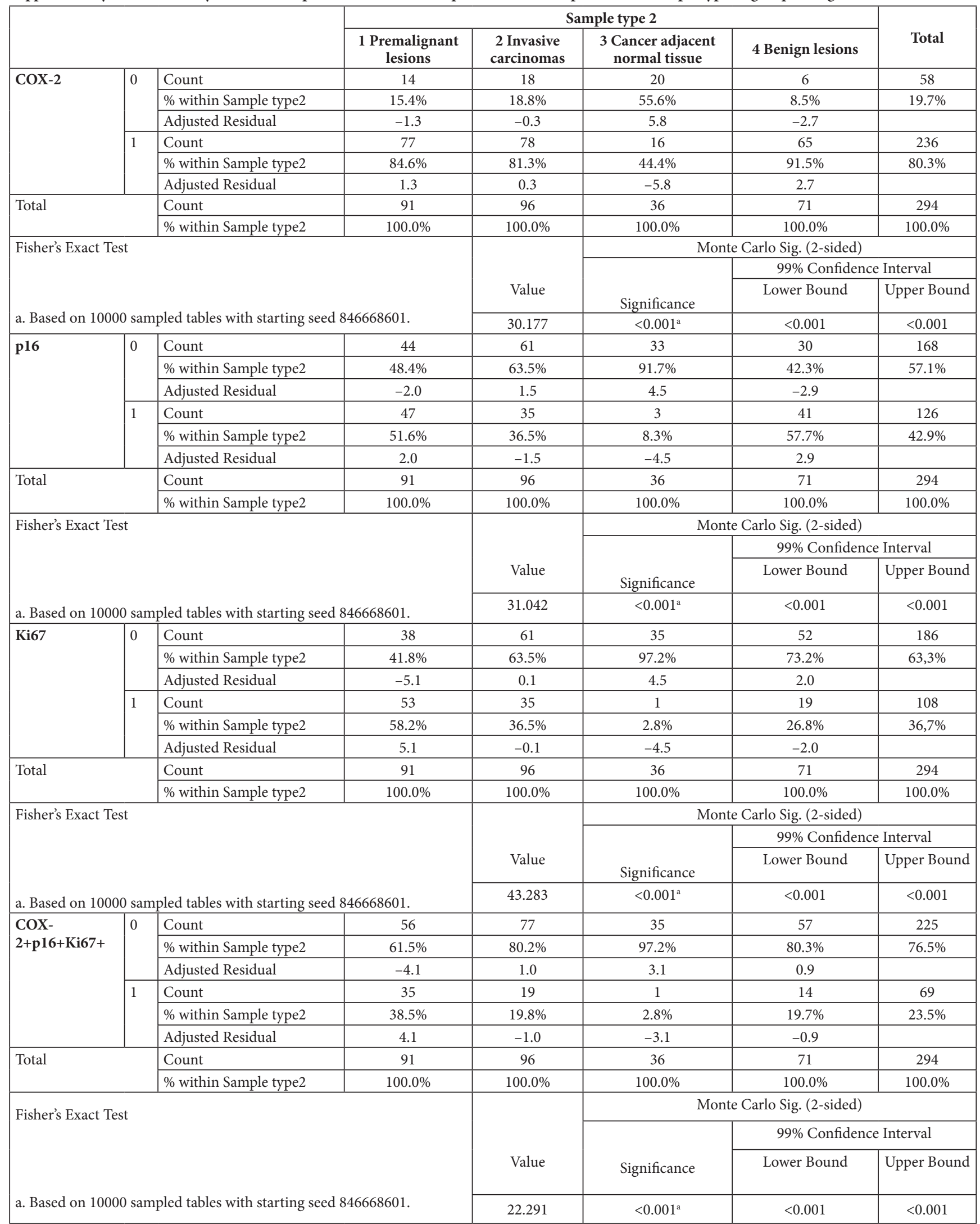


Supplementary Table S3. Comparison of each two particular subgroups within "sample type 1" using the Fisher's exact test with significant level 0.05. For significant values was used bold for emphasis.

\begin{tabular}{|c|c|c|c|c|}
\hline COX 2 comparison & Odds ratio & Lower bound & Upper bound & p-value \\
\hline Flat_epithelial_atypia vs. Atypical_ductal_hyperplasia & 3.22 & 0.203 & 201 & 0.582 \\
\hline Flat_epithelial_atypia vs. DCIS & 2.62 & 0.375 & 14.1 & 0.192 \\
\hline Flat_epithelial_atypia vs. Invasive_carcinoma & 1.85 & 0.281 & 9.11 & 0.411 \\
\hline Flat_epithelial_atypia vs. Cancer_adjacent_normal_tissue & 0.351 & 0.0504 & 1.85 & 0.284 \\
\hline Flat_epithelial_atypia vs. Benign_leisons & 4.51 & 0.601 & 27.8 & 0.077 \\
\hline Flat_epithelial_atypia vs. Fatty tissue & 0.186 & 0.0197 & 1.33 & 0.095 \\
\hline Atypical_ductal_hyperplasia vs. DCIS & 0.777 & 0.0159 & 6.99 & 1 \\
\hline Atypical_ductal_hyperplasia vs. Invasive_carcinoma & 0.544 & 0.0115 & 4.52 & 1 \\
\hline Atypical_ductal_hyperplasia vs. Cancer_adjacent_normal_tissue & 0.105 & 0.00215 & 0.916 & 0.026 \\
\hline Atypical_ductal_hyperplasia vs. Benign_leisons & 1.35 & 0.0262 & 13.7 & 0.581 \\
\hline Atypical_ductal_hyperplasia vs. Fatty_tissue & 0.0585 & 0.00103 & 0.657 & 0.009 \\
\hline DCIS vs. Invasive_carcinoma & 0.700 & 0.268 & 1.74 & 0.531 \\
\hline DCIS vs. Cancer_adjacent_normal_tissue & 0.132 & 0.0452 & 0.362 & $<0.001$ \\
\hline DCIS vs. Benign_leisons & 1.74 & 0.535 & 6.19 & 0.427 \\
\hline DCIS vs. Fatty_tissue & 0.0678 & 0.0129 & 0.288 & $<0.001$ \\
\hline Invasive_carcinoma vs. Cancer_adjacent_normal_tissue & 0.189 & 0.0739 & 0.461 & $<0.001$ \\
\hline Invasive_carcinoma vs. Benign_leisons & 2.50 & 0.880 & 8.12 & 0.075 \\
\hline Invasive_carcinoma vs. Fatty_tissue & 0.0951 & 0.0195 & 0.375 & $<0.001$ \\
\hline Cancer_adjacent_normal_tissue vs. Benign_leisons & 13.1 & 4.24 & 46.8 & $<0.001$ \\
\hline Cancer_adjacent_normal_tissue vs. Fatty_tissue & 0.508 & 0.0972 & 2.19 & 0.353 \\
\hline Benign_leisons vs. Fatty_tissue & 0.040 & 0.00678 & 0.185 & $<0.001$ \\
\hline p16 comparison & Odds ratio & Lower bound & Upper bound & p-value \\
\hline Flat_epithelial_atypia vs. Atypical_ductal_hyperplasia & 1.93 & 0.226 & 19.3 & 0.650 \\
\hline Flat_epithelial_atypia vs. DCIS & 1 & 0.210 & 4.76 & 1 \\
\hline Flat_epithelial_atypia vs. Invasive_carcinoma & 0.578 & 0.123 & 2.69 & 0.499 \\
\hline Flat_epithelial_atypia vs. Cancer_adjacent_normal_tissue & 0.0984 & 0.0114 & 0.677 & 0.007 \\
\hline Flat_epithelial_atypia vs. Benign_leisons & 1.36 & 0.285 & 6.49 & 0.740 \\
\hline Flat_epithelial_atypia vs. Fatty_tissue & 0.289 & 0.0311 & 2.18 & 0.204 \\
\hline Atypical_ductal_hyperplasia vs. DCIS & 0.504 & 0.0757 & 2.58 & 0.485 \\
\hline Atypical_ductal_hyperplasia vs. Invasive_carcinoma & 0.290 & 0.0443 & 1.46 & 0.149 \\
\hline Atypical_ductal_hyperplasia vs. Cancer_adjacent_normal_tissue & 0.0514 & 0.00503 & 0.373 & 0.001 \\
\hline Atypical_ductal_hyperplasia vs. Benign_leisons & 0.686 & 0.103 & 3.53 & 0.730 \\
\hline Atypical_ductal_hyperplasia vs. Fatty_tissue & 0.151 & 0.0139 & 1.21 & 0.077 \\
\hline DCIS vs. Invasive_carcinoma & 0.577 & 0.294 & 1.12 & 0.085 \\
\hline DCIS vs. Cancer_adjacent_normal_tissue & 0.0927 & 0.0167 & 0.337 & $<0.001$ \\
\hline DCIS vs. Benign_leisons & 1.36 & 0.671 & 2.79 & 0.403 \\
\hline DCIS vs. Fatty_tissue & 0.278 & 0.0458 & 1.17 & 0.078 \\
\hline Invasive_carcinoma vs. Cancer_adjacent_normal_tissue & 0.160 & 0.0293 & 0.569 & 0.001 \\
\hline Invasive_carcinoma vs. Benign_leisons & 2.38 & 1.21 & 4.69 & 0.009 \\
\hline Invasive_carcinoma vs. Fatty_tissue & 0.478 & 0.0803 & 1.98 & 0.372 \\
\hline Cancer_adjacent_normal_tissue vs. Benign_leisons & 14.7 & 4.031 & 81.7 & $<0.001$ \\
\hline Cancer_adjacent_normal_tissue vs. Fatty_tissue & 2.92 & 0.341 & 25.2 & 0.331 \\
\hline Benign_leisons vs. Fatty_tissue & 0.203 & 0.0335 & 0.859 & 0.018 \\
\hline Ki67 comparison & Odds ratio & Lower bound & Upper bound & p-value \\
\hline Flat_epithelial_atypia vs. Atypical_ductal_hyperplasia & 1.93 & 0.0840 & 132 & 1 \\
\hline Flat_epithelial_atypia vs. DCIS & 0.268 & 0.0260 & 1.47 & 0.105 \\
\hline Flat_epithelial_atypia vs. Invasive_carcinoma & 0.146 & 0.0143 & 0.788 & 0.014 \\
\hline Flat_epithelial_atypia vs. Cancer_adjacent_normal_tissue & 0.00960 & 0.000166 & 0.113 & $<0.001$ \\
\hline Flat_epithelial_atypia vs. Benign_leisons & 0.0945 & 0.00901 & 0.530 & 0.002 \\
\hline Flat_epithelial_atypia vs. Fatty_tissue & 0.0791 & 0.00533 & 0.668 & 0.011 \\
\hline Atypical_ductal_hyperplasia vs. DCIS & 0.135 & 0.00290 & 1.09 & 0.040 \\
\hline Atypical_ductal_hyperplasia vs. Invasive_carcinoma & 0.0733 & 0.00159 & 0.585 & 0.003 \\
\hline
\end{tabular}




\section{Supplementary Table S3. Cotinued ...}

\begin{tabular}{|c|c|c|c|c|}
\hline COX 2 comparison & Odds ratio & Lower bound & Upper bound & p-value \\
\hline Atypical_ductal_hyperplasia vs. Cancer_adjacent_normal_tissue & 0.00576 & 0000899E-05 & 0.0826 & $<0.001$ \\
\hline Atypical_ductal_hyperplasia vs. Benign_leisons & 0.0477 & 0.00102 & 0.393 & 0.001 \\
\hline Atypical_ductal_hyperplasia vs. Fatty_tissue & 0.0419 & 0.000715 & 0.489 & 0.003 \\
\hline DCIS vs. Invasive_carcinoma & 0.545 & 0.278 & 1.06 & 0.066 \\
\hline DCIS vs. Cancer_adjacent_normal_tissue & 0.0277 & 0.000653 & 0.184 & $<0.001$ \\
\hline DCIS vs. Benign_leisons & 0.348 & 0.161 & 0.735 & 0.003 \\
\hline DCIS vs. Fatty_tissue & 0.262 & 0.0433 & 1.10 & 0.047 \\
\hline Invasive_carcinoma vs. Cancer_adjacent_normal_tissue & 0.0505 & 0.00119 & 0.329 & $<0.001$ \\
\hline Invasive_carcinoma vs. Benign_leisons & 0.640 & 0.306 & 1.305 & 0.241 \\
\hline Invasive_carcinoma vs. Fatty_tissue & 0.478 & 0.0803 & 1.98 & 0.372 \\
\hline Cancer_adjacent_normal_tissue vs. Benign_leisons & 12.7 & 1.83 & 545 & 0.003 \\
\hline Cancer_adjacent_normal_tissue vs. Fatty_tissue & 9.03 & 0.652 & 513 & 0.061 \\
\hline Benign_leisons vs. Fatty_tissue & 0.750 & 0.121 & 3.27 & 1 \\
\hline COX_2_p16_Ki67 comparison & Odds ratio & Lower bound & Upper bound & p-value \\
\hline Flat_epithelial_atypia vs. Atypical_ductal_hyperplasia & 2.82 & 0.336 & 29.4 & 0.377 \\
\hline Flat_epithelial_atypia vs. DCIS & 0.800 & 0.171 & 4.23 & 0.738 \\
\hline Flat_epithelial_atypia vs. Invasive_carcinoma & 0.374 & 0.0793 & 1.99 & 0.220 \\
\hline Flat_epithelial_atypia vs. Cancer_adjacent_normal_tissue & 0.0477 & 0.000855 & 0.582 & 0.007 \\
\hline Flat_epithelial_atypia vs. Benign_leisons & 0.374 & 0.0760 & 2.05 & 0.218 \\
\hline Flat_epithelial_atypia vs. Fatty_tissue & 0.266 & 0.0189 & 2.48 & 0.192 \\
\hline Atypical_ductal_hyperplasia vs. DCIS & 0.271 & 0.0403 & 1.39 & 0.080 \\
\hline Atypical_ductal_hyperplasia vs. Invasive_carcinoma & 0.128 & 0.0188 & 0.657 & 0.005 \\
\hline Atypical_ductal_hyperplasia vs. Cancer_adjacent_normal_tissue & 0.0176 & 0.000311 & 0.203 & $<0.001$ \\
\hline Atypical_ductal_hyperplasia vs. Benign_leisons & 0.127 & 0.0183 & 0.681 & 0.006 \\
\hline Atypical_ductal_hyperplasia vs. Fatty_tissue & 0.0961 & 0.00626 & 0.867 & 0.023 \\
\hline DCIS vs. Invasive_carcinoma & 0.466 & 0.217 & 0.988 & 0.034 \\
\hline DCIS vs. Cancer_adjacent_normal_tissue & 0.0548 & 0.00128 & 0.367 & $<0.001$ \\
\hline DCIS vs. Benign_leisons & 0.464 & 0.199 & 1.05 & 0.066 \\
\hline DCIS vs. Fatty_tissue & 0.318 & 0.0320 & 1.59 & 0.210 \\
\hline Invasive_carcinoma vs. Cancer_adjacent_normal_tissue & 0.118 & 0.00271 & 0.796 & 0.014 \\
\hline Invasive_carcinoma vs. Benign_leisons & 0.995 & 0.423 & 2.29 & 1 \\
\hline Invasive_carcinoma vs. Fatty_tissue & 0.679 & 0.0681 & 3.46 & 1 \\
\hline Cancer_adjacent_normal_tissue vs. Benign_leisons & 8.49 & 1.19 & 373 & 0.019 \\
\hline Cancer_adjacent_normal_tissue vs. Fatty_tissue & 5.59 & 0.269 & 353 & 0.187 \\
\hline Benign_leisons vs. Fatty_tissue & 0.681 & 0.0667 & 3.64 & 1 \\
\hline
\end{tabular}


Supplementary Table S4. Comparison of each two particular subgroups within "sample type 2" using the Fisher's exact test with significant level 0.05 . For significant values was used bold for emphasis.

\begin{tabular}{|c|c|c|c|c|}
\hline COX 2 comparison & Odds ratio & Lower bound & Upper bound & p-value \\
\hline Premalignant lesions vs. Invasive carcinoma & 0.789 & 0.337 & 1.81 & 0.566 \\
\hline Premalignant lesions vs. Cancer_adjacent_normal_tissue & 0.148 & 0.0557 & 0.379 & $<0.001$ \\
\hline Premalignant lesions vs. Benign_leisons & 1.96 & 0.662 & 6.60 & 0.232 \\
\hline Invasive carcinoma vs. Cancer_adjacent_normal_tissue & 0.188 & 0.0739 & 0.461 & $<0.001$ \\
\hline Invasive carcinoma vs. Benign_leisons & 2.49 & 0.880 & 8.12 & 0.075 \\
\hline Cancer_adjacent_normal_tissue vs. Benign_leisons & 13.1 & 4.24 & 46.8 & $<0.001$ \\
\hline \multicolumn{5}{|l|}{ p16 comparison } \\
\hline Premalignant lesions vs. Invasive carcinoma & 0.539 & 0.287 & 1.0038 & 0.040 \\
\hline Premalignant lesions vs. Cancer_adjacent_normal_tissue & 0.0866 & 0.0159 & 0.306 & $<0.001$ \\
\hline Premalignant lesions vs. Benign_leisons & 1.28 & 0.654 & 2.51 & 0.525 \\
\hline Invasive carcinoma vs. Cancer_adjacent_normal_tissue & 0.160 & 0.0293 & 0.569 & 0.001 \\
\hline Invasive carcinoma vs. Benign_leisons & 2.37 & 1.21 & 4.69 & 0.008 \\
\hline Cancer_adjacent_normal_tissue vs. Benign_leisons & 14.7 & 4.03 & 81.7 & $<0.001$ \\
\hline \multicolumn{5}{|l|}{ Ki67 comparison } \\
\hline Premalignant lesions vs. Invasive carcinoma & 0.413 & 0.219 & 0.772 & 0.003 \\
\hline Premalignant lesions vs. Cancer_adjacent_normal_tissue & 0.0210 & 0.000501 & 0.136 & $<0.001$ \\
\hline Premalignant lesions vs. Benign_leisons & 0.264 & 0.126 & 0.538 & $<0.001$ \\
\hline Invasive carcinoma vs. Cancer_adjacent_normal_tissue & 0.0505 & 0.00119 & 0.329 & $<0.001$ \\
\hline Invasive carcinoma vs. Benign_leisons & 0.639 & 0.306 & 1.31 & 0.241 \\
\hline Cancer_adjacent_normal_tissue vs. Benign_leisons & 12.6 & 1.83 & 545 & 0.003 \\
\hline \multicolumn{5}{|l|}{ COX_2_p16_Ki67 comparison } \\
\hline Premalignant lesions vs. Invasive carcinoma & 0.413 & 0.219 & 0.772 & 0.003 \\
\hline Premalignant lesions vs. Cancer_adjacent_normal_tissue & 0.0210 & 0.000501 & 0.136 & $<0.001$ \\
\hline Premalignant lesions vs. Benign_leisons & 0.264 & 0.126 & 0.538 & $<0.001$ \\
\hline Invasive carcinoma vs. Cancer_adjacent_normal_tissue & 0.051 & 0.00119 & 0.329 & $<0.001$ \\
\hline Invasive carcinoma vs. Benign_leisons & 0.639 & 0.306 & 1.31 & 0.241 \\
\hline Cancer_adjacent_normal_tissue vs. Benign_leisons & 12.6 & 1.83 & 545 & 0.003 \\
\hline
\end{tabular}

